\title{
UNCERTAINTY MODELLING OF CITIZEN-CENTERED GROUP DECISION MAKING USING FUZZY-VIKOR CASE STUDY: SITE SELECTION OF HEALTHCARE SERVICES
}

\author{
Z. Neisani Samani ${ }^{1}$, A. A. Alesheikh ${ }^{2, *}$ \\ ${ }^{1}$ Dept. of Natural Resources and Environment, Science and Research Branch, Islamic Azad University, Tehran, Iran- \\ zeinab.neisani@srbiau.ac.ir \\ ${ }^{2}$ Dept. of GIS, Geodesy and Geomatics Engineering Faculty, K. N. Toosi University of Technology, Tehran, Iran- \\ alesheikh@kntu.ac.ir
}

KEY WORDS: Uncertainty, Site Selection, Fuzzy-VIKOR, Citizen-Centered Tehran, Group Decision Making, Healthcare Services

\begin{abstract}
:
The participation of citizens in decision-making processes is one of the main concerns in urban planning. People's contributions increase the usability and efficiency of urban facilities. Hospitals and healthcare services are among the most important public facilities that citizens require. This paper aims to improve an approach that could locate the hospitals according to the citizens' preferences. Decision-making process in this situation should consider the uncertainties exist in any steps of decisions-making. In this regard, this paper applied Fuzzy-VIKOR method that is appropriate to model such kind of uncertainty. The proposed method was accomplished in Districts 6 of Tehran province. The achieved results were compared with each other in two different scenario (using expert knowledge and citizens' satisfaction). The comparison of the results showed that the more suitable distribution and density of proposed sites for hospitals must be observed if the citizens' perspectives were considered. Also, the proposed sites with experts follow urban planning principals rather than the second case.
\end{abstract}

\section{INTRODUCTION}

Site selection specifies the act of new facility location, mutually for business and government. Site selection includes measuring the requirements of a new project compared to the merits of possible locations. The task came of age during the 20th century, as governments and corporate operations expanded to new geographies on a national and international scale (Neisani Samani et al., 2018).

Site selection of new hospitals is one of the vital decisions considered by urban and health policymakers. The priority of healthcare services is to provide the right service to all citizens at all times in the right places (Chatterjee, Mukherjee, 2013). Optimal site selection is critical and important for usefulness and fairness of healthcare amenities. Usually, the site selection process is done using expert knowledge (Davtalab, Alesheikh, 2019); however investigating of related researches showed that in site selection of public facilities, the viewpoint of citizens is also importance (Bolouri et al., 2018). One of these facilities is hospital and healthcare services. Therefore, this paper aims to compare the selected sites introduced by the experts' knowledge and citizens' idea in order to provide more suitable locations. The main contribution of this paper is the uncertainty modeling of the process of group decision making in both cases.

The literature offers some different suggestions for citizencentered group decision making. For example, Santos et al. (2018) analyzed the use of Public Participatory Geographic Information System (PPGIS), as a tool to include citizens in the discussion through a web-based system. The results show that the system is efficient and can initiate more people in the urban planning process on the impact noise area. Rall et al. (2019) studied the added value of PPGIS, a relatively new type of survey for obtaining social values, as a tool for UGI planning. According to Horgan and Dimitrijević (2019) studied on the tools and technologies used for participatory processes in sustainable urban planning.

In recent years, some researches have been done concerning site selection for healthcare services. In a study conducted by Shahabi et al. (2012) studied on determining suitable locations for construction of suitable disposal centers. The suitable sits for the waste substance access center were selected using each model. Chatterjee and Mukherjee (2013) studied to perform a multicriteria evaluation of potential hospital locations using Fuzzy Analytical Hierarchy Process (FAHP) using a case of three potential rural sites in India. Senvar et al. (2016) studied handles the problem of establishing a well-organized and distributed network of a hospital that delivers its services to the target population. They offered a new multicriteria decision making (MCDM) process that integrates Hesitant Fuzzy Sets (HFSs) to Technique for Order Preference by Similarity to Ideal Solution (TOPSIS). Sahin et al. (2019) studied a decision support model for site selection to establish a new hospital based on the analytic hierarchy process (AHP).

Dadzie et al. (2014) studied a Fuzzy-VIKOR frame for measuring and ranking internet health data providers down a fuzzy environment in which uncertainties and subjectivities are provided for with linguistic variables. Linguistic variables with Triangular Fuzzy Numbers (TFN) are used to evaluate weights of the evaluation criteria and the rankings of each internet health information provider. Zhou et al. (2018) studied mobile robot

${ }^{*}$ Corresponding author 
selection as a MCDM problem. The VIKOR-based implementation steps integrating fuzzy extended AHP technique are developed.

In this study, Fuzzy-VIKOR methods were used to recognize and prioritize citizen needs. In this regard, first, six main criteria were considered including population, distance to the main roads, distance to the current healthcare services, distance to the metro stations, distance to the bus stations and traffic congestion. Then, in two different scenarios the opinions of the (1) urban planning experts and (2) citizens of the case study area, were collected using Fuzzy-VIKOR approach. In both scenarios, suitable places were determined and assessed. The comparison of the results showed that the more suitable distribution and density of proposed sites for hospitals must be observed if the citizens' perspectives were measured. Correspondingly, the proposed sites with experts follow urban planning principals rather than the second case.

\section{MATERIALS AND METHODS}

These sections explain the main concepts of the research including citizens' participation in site selection, VIKOR and also Fuzzy-VIKOR. Then it declares the proposed methodology.

\subsection{Citizens' Participation in Site Selection Task}

The participation of citizens in urban decision-making is a crucial element of urban policy. It raises transparency and makes urban managers more responsible for their decisions (Lowndes et al., 2001). One of the most effective methods to increase participation and involve citizens in urban decision-making, along with improving the stability and safety of the communities, is site selection. This needs a supportable and planned effort of the organizations involved at both local and central levels. It also involves a continuous readjustment of the associations between different stakeholders, over permanent communication (Honarparvar et al., 2018).

Citizens' participation is seen is a kind of citizen power (Arnstein, 1969) it is the rearrangement of power that enables the citizens, to be deliberately convoluted. It is the strategy by which have-nots join in defining how material is shared, goals and strategies are established, tax funds are owed, programs are functioned, and aids like agreements and benefaction are parcelled out. Citizens' participation is also realized as an energetic feature of good urban management (Lawton, Macaulay, 2013).

In this regards, site selection of different is a special task of urban managers that involves measuring the needs of a planned facility contrary to the qualities of potential locations (Vahidnia et al., 2008). It covers the selection of a part of property for any structure consistent with prevailing security codes. The enclosure of safety in site selection is accepted as imperative for sustainability (Rajendran, 2006).

\subsection{Vikor and Fuzzy-Vikor}

The VIKOR Method was first introduced by Epicorovich in 1998. The VlseKriterijumska Optimizacija Kompromisno Resenje (VIKOR) means multicriteria optimization and reconciliation. VIKOR is a helpful tool in MCDM optimization of complex systems, particularly in a situation where the decision-maker is not able, or does not know, to express his/her preference at the beginning of system design. The obtained compromise solution could be accepted by the decision-makers (Opricovic, 2011).

The VIKOR approach is an operative MCDM means, particularly when the decision-maker is not able, or does not know to express his/her preference at the beginning of system design (Anojkumar et al., 2014). In VIKOR method, the performance scores of the alternatives with respect to a set of criteria are measured as crisp principles. But, under many situations, crisp data are insufficient to model real life conditions. Furthermore, in case of inconsistent situations or criteria, the decision-maker must similarly study vague or unclear data (Maji, 2012).

The compromise solutions could be the basis for negotiations, involving the decision-makers' preference by criteria weights. The Fuzzy-VIKOR technique can solve fuzzy multicriteria problems with conflicting and non-commensurable (different units) criteria. VIKOR method used to rank and choice the best places from several places according to the closeness to the best solution (Anojkumar et al., 2014).

Assuming that each alternative is evaluated according to each criterion function, the compromise ranking could be performed by comparing the measure of closeness to the ideal alternative. Its ranking indexes similarly take into consideration the maximum group utility and minimal individual regret. It defines the compromise ranking list, the compromise solution, and the weight constancy intervals for preference constancy of the compromise solution taken with the given weights. The analysis of weight stability intervals for a single criterion is performed for all criterion functions, with the same initial values of weights (Anojkumar et al., 2014).

In this way, the preference stability of an obtained compromise solution may be analysed using the VIKOR program. The concept of intuitionistic fuzzy sets is applied to VIKOR in this study. The design steps are (Opricovic, 2011):

Step 1: Integrate the intuitionistic fuzzy F (k) matrix as Eq.1 (m and $\mathrm{n}$ are the number of criteria and the user):

$$
\mathrm{F}^{(\mathrm{k})}=\left(\mathrm{f}_{\mathrm{ij}}^{(\mathrm{k})}\right)_{\mathrm{m} \times \mathrm{n}}
$$

Step 2: Compute the crisp decision-making matrix $\mathrm{F}$ based on Eq. (2):

$$
F=\left(f_{i j}\right)_{m \times n}
$$

Step 3: Acquire the positive A+ and negative A- ideal solution using Eq. (3) and Eq. (4):

$$
\begin{aligned}
& A^{+}=\left\{A_{1}^{+}, A_{2}^{+}, \ldots, A_{n}^{+}\right\} \\
& A^{-}=\left\{A_{1}^{-}, A_{2}^{-}, \ldots, A_{n}^{-}\right\}
\end{aligned}
$$

Step 4: Calculate the group benefit value $(\mathrm{Si})$ and individual regret value $(\mathrm{Ri})$ of every alternative.

Step 5: Compute the compromise value (Qi) of every alternative (i is the number of alternatives).

Step 6: Rank the alternatives based on the Qi values and select the best alternative. The smaller the $\underline{Q}$ value, the better the alternative; the bigger the value, the worthier the alternative. 
Step7: Set $\Delta \mathrm{Q}=\mathrm{Q}\left(\mathrm{A}_{2}\right)-\mathrm{Q}\left(\mathrm{A}_{1}\right)-1 /(\mathrm{i}-1)$. Propose a compromise solution the alternative $\left(\mathrm{A}_{1}\right)$ which is the best ranked by the measure $\mathrm{Q}$ (minimum) if the following two conditions are satisfied:

Acceptable advantage: $Q\left(A_{2}\right)-Q\left(A_{1}\right) \geq 1 /(i-1)$, whereas $A_{2}$ has the 2nd position in the ranking list by $\mathrm{Q}$.

\subsection{Proposed Methodology}

The purpose of this article is to solve the problem of urban site selection by using PPGIS through Fuzzy-VIKOR method. The method used is designed as shown in Figure 1.

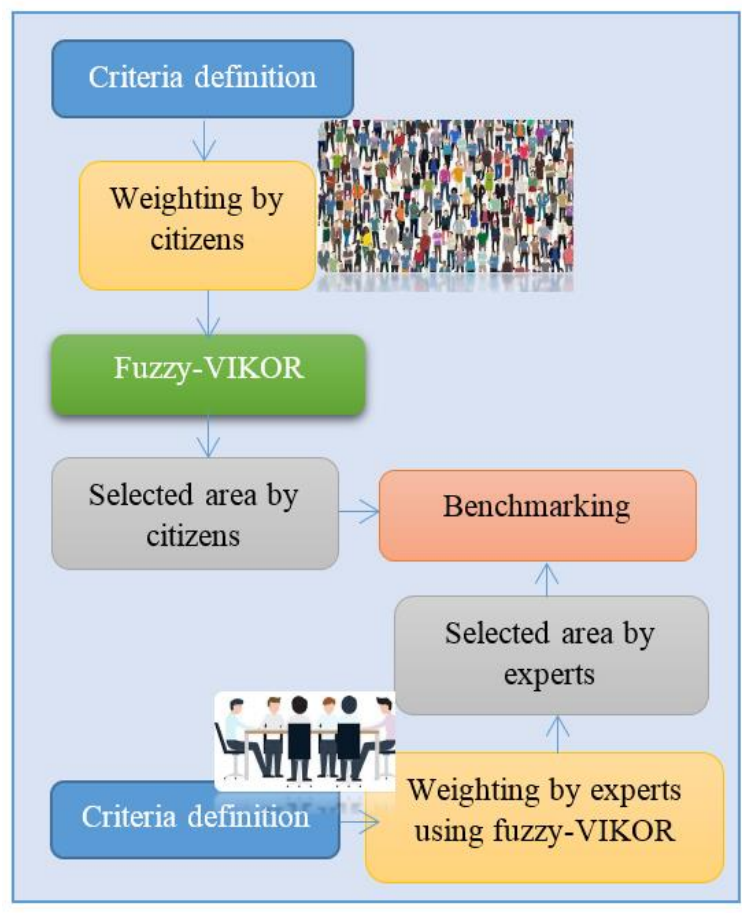

Figure1. Methodology used

According to Figure 1, the first stage of the proposed method is revealed to the specification of the effective criteria. In this regard, 15 different experts in site selection of healthcare services confirmed the driven criteria from the literatures and also modified some of them. Finally, the effective criteria are defined as follows:

- Population density: the higher population density will cause a greater number of casualties during an earthquake, relief operations will be more difficult and evacuation of buildings will take a longer time.

- Distance to the main road: Usually all the patient have more feasible access to the main roads. Therefore proximity to the main road is one of the key factors on selecting appropriated place for healthcare services.

- Distance to the current healthcare services: In order to distribute the healthcare services considering spatial justice. Due to urban planning principals, space being an essential aspect of human societies, social justice is surrounded on it. Thus the consideration of relations between space and societies is vital to the consideration of social. This reflection can be directed by the conception of spatial justice that links Social Justice with space. Spatial justice is a crucial challenge because it is the final aim of many urban planning strategies.

- Distance to the metro station: Transport accessibility is a very significant challenge for location estimation. Any freshly launched transport system that meaningfully advances accessibility increases exposure to potential clients and is helpful to nearby facilities. As one of the main factor for transportation in Tehran province is Metro transportation, so the proximity to the metro stations makes the healthcare services more applicable.

- Distance to the bus station: The other public transportation vehicle in Tehran province is bus transportation, so the proximity to the bus stations makes the healthcare services more valid.

- Traffic congestion: Traffic congestion is a situation on transportation that as use growths, and is considered by slower speeds, extensive tour times, and enlarged vehicular queuing. Once traffic demand is great enough that the communication between cars reduces the speed of the traffic flow, this consequences in some congestion. Therefore having light congestion would increase the efficiency of these public services.

Then two scenarios were defined. In the first scenario, only the experts weight the effective criteria and in the second case, only citizens opined about the factors.

\section{IMPLEMENTATION AND RESULTS}

This section first describes the case study area and then illustrates the implementation results.

\subsection{Study Area}

District 6 of Tehran province is approximately located in the center of the city. This district has a zone of equivalent to 2138.45 hectares, about $3.3 \%$ of the through the city. Latest statistics show that the district with a limited area of 20 square kilometers has a population of over 250 thousand people. This district from the three directions of the west, east and north is limited to three main highways of Chamran, Modarres, and Hemmat and in the south to the largest east-west junction, namely Enqelab Avenue. It consists of 6 operational metro lines (and an additional commuter rail line), with construction underway on three lines including the west extension of line 4 , line 6 and north and east extension line 7 (Naserbakht, 2012). 


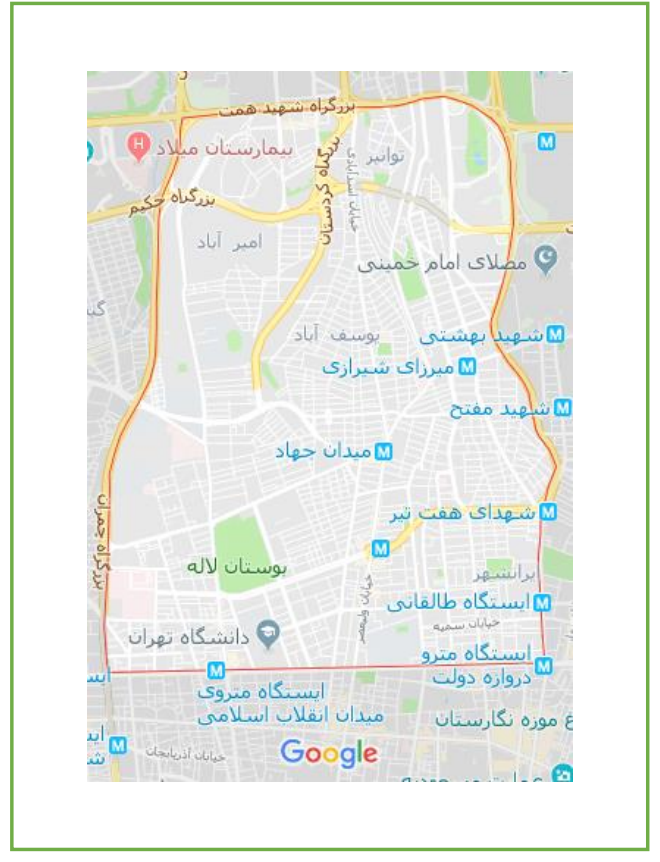

Figure2. District 6 of Tehran province

\subsection{Required Data}

The proposed method was implemented in Districts 6 of Tehran province. In this study, the weights of the indicators and the scores of each evaluation index corresponding to the program were carried out in both scenarios. At first 15 urban planning experts that were familiar with the case study area fulfilled the questionnaires. Second seventy citizens form the case study area completed the forms. They made a semantic evaluation based on the nature of each evaluation index. The semantic evaluation scale is shown in Table 1.

\begin{tabular}{|l|c|}
\hline Linguistic variables & Fuzzy numbers \\
\hline Very importance & $(0.90,0.05,0.05)$ \\
\hline Importance & $(0.75,0.20,0.05)$ \\
\hline Medium & $(0.50,0.40,0.10)$ \\
\hline Unimportance & $(0.25,0.6,0.15)$ \\
\hline Very unimportance & $(0.10,0.80,0.10)$ \\
\hline
\end{tabular}

Table 1. Fuzzy linguistic scale for direct-relation of criteria

Final weights of the criteria were computed according to the Table 2 and Table 3:

\begin{tabular}{|l|c|}
\hline Criteria & Weight \\
\hline Population & 0.16 \\
\hline Distance to the main road & 0.22 \\
\hline Distance to the current healthcare services & 0.09 \\
\hline Distance to the metro station & 0.24 \\
\hline Distance to the bus station & 0.14 \\
\hline Traffic congestion & 0.15 \\
\hline
\end{tabular}

Table 2. Weights of the criteria (scenario\#1)

\begin{tabular}{|l|c|}
\hline Criteria & Weight \\
\hline Population & 0.15 \\
\hline Distance to the main road & 0.18 \\
\hline Distance to the current healthcare services & 0.11 \\
\hline Distance to the metro station & 0.25 \\
\hline Distance to the bus station & 0.13 \\
\hline Traffic congestion & 0.18 \\
\hline \multicolumn{2}{|c|}{ Table 3. Weights of the criteria (scenario\#2) }
\end{tabular}

The achieved weights were multiplied in normalized map layers of the criteria using a weighted linear combination method. Respectively, the final selected areas in the first scenario and the second one are illustrated in Figure 3 and Figure 4.

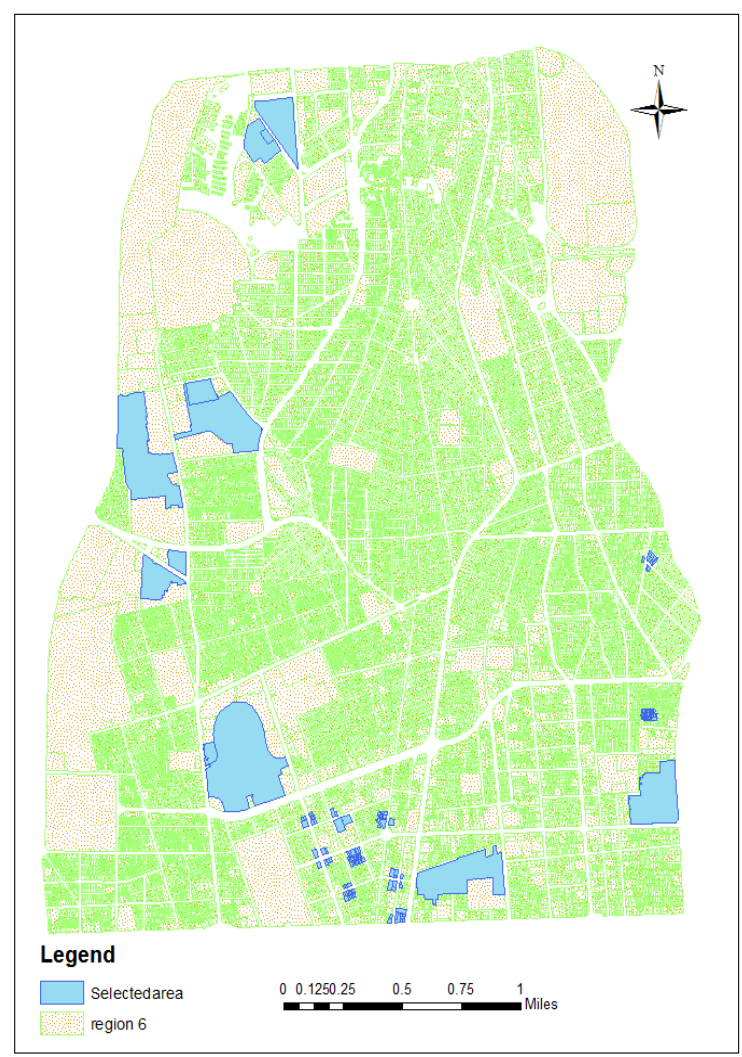

Figure3. Appropriate sites for healthcare services (scenario\#1) 


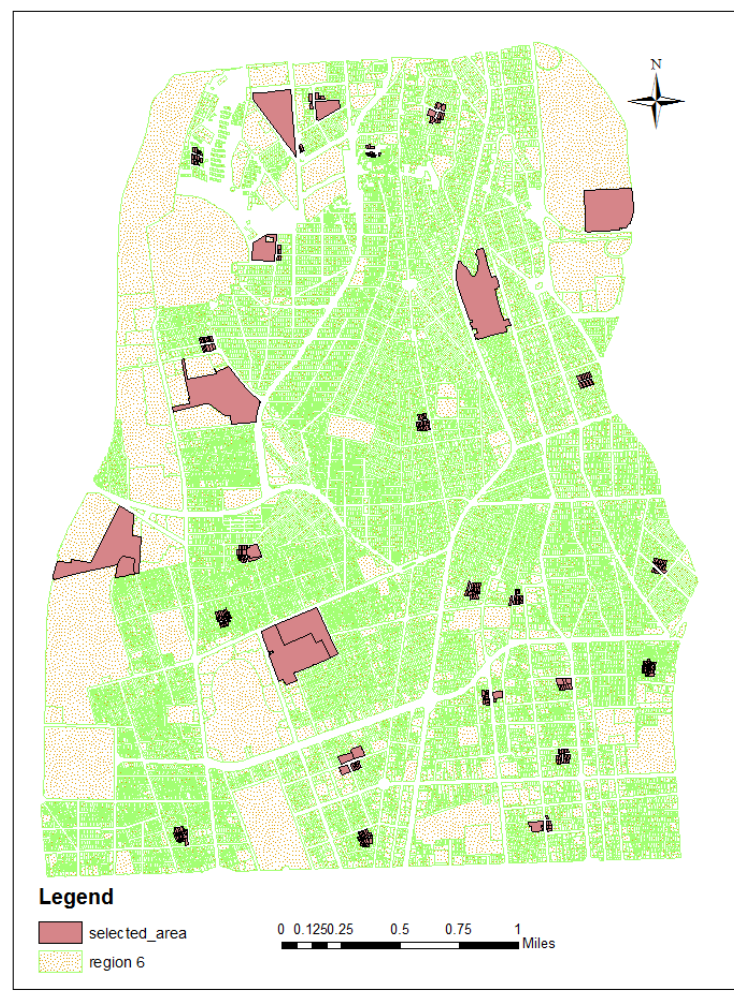

Figure 4. Appropriate sites for healthcare services (scenario\#2)

\section{CONCLUSIONS AND FUTURE WORKS}

Hospitals and healthcare services are considered as one of the most important public facilities that usually all people need. This study proposed an approach to locate the hospitals according to the citizens' preferences and expert knowledge. Decisionmaking process in this situation should manage the uncertainties of different kinds of citizens' preferences. In this regard, the paper applied intuitionistic Fuzzy-VIKOR method that is able to model the multicriteria uncertainty. The achieved results were compared with each other in two different scenarios. The comparison of the results showed that the more suitable distribution and density of proposed sites for the hospital can be achieved when the citizens' perspectives were considered. Also, the proposed sites with experts obeyed urban planning principals. As future researches, integration of citizens and exert knowledge in order to achieve more accurate and efficient area are recommended.

\section{REFERENCES}

Anojkumar, L., Ilangkumaran, M., \& Sasirekha, V., 2014. Comparative analysis of MCDM methods for pipe material selection in sugar industry. Expert Systems with Applications, 41(6), 2964-2980.

Arnstein, S.R., 1969. A ladder of citizen participation. J. Am. Inst. Plan. 35, 216-224.

Bolouri, S., Vafaeinejad ,A., Alesheikh, A. A., Aghamohammadi, H., 2018. The Ordered Capacitated MultiObjective Location-Allocation Problem for Fire Stations Using Spatial Optimization. International Journal of Geo-Information. Vol. 7(2), No. 44. pp 1 - 20. Doi: 10.3390/ijgi7020044.
Chatterjee, D., Mukherjee, B., 2013. Potential Hospital Location Selection Using Fuzzy-AHP: An Empirical Study in Rural India. International Journal of Innovative Technology and Research (IJITR). Vol No. 1, Issue No. 4, June - July 2013, 304 - 314.

Dadzie, E., Nabareseh, S., Oplatková, Z. K., 2014. Fuzzy VIKOR approach: Evaluating quality of internet health information. Federated Conference on Computer Science and Information Systems, Warsaw, 2014, pp. 183-190. Doi: 10.15439/2014F203.

Davtalab, M. and Alesheikh, A. A., 2019. A Spatial Filtering Model in Recommender Systems Using Fuzzy Approach. International Journal of Uncertainty Fuzziness and KnowledgeBased Systems. Vol 27, No 3, Jun 2019.

Honarparvar, S., Forouzandeh Jonaghani, R., Alesheikh, A. A., Atazadeh, B., 2018. Improvement of a Location-Aware Recommender System Using Volunteered Geographic Information. Geocarto International. DOI: 10.1080/10106049.2018.1493155.

Horgan, D. and Dimitrijevi', B., 2019. Frameworks for citizens participation in planning: From conversational to smart tools. Sustainable Cities and Society, https://doi.org/10.1016/j.scs.2019.101550.

Lowndes, V., Pratchett, L., Stoker, G., 2002. Trends in public participation: part1- local government perspectives. Public Administration. $\quad$ vol $79 \quad$ (1), 205-222. https://doi.org/10.1111/1467-9299.00253.

Lawton, A., and Macaulay, M., 2013. Localism in Practice: Investigating Citizen Participation and Good Governance in Local Government Standards of Conduct. Public Administration Review. 74 (1).https://doi.org/10.1111/puar.12161

Maji, L., 2012. A note on "A modified VIKOR multiple-criteria decision method for improving domestic airlines service quality". Journal of Air Transport Management. https://doi.org/10.1016/j.jairtraman.2011.06.002.

Naserbakht, M. Application for the District 6 of Municipality of Tehran to become a Member of the International Safe Community Network. Community safe area 6 Municipality of Tehran: Tehran, Iran, 2012.

Neisani Samani, Z., Karimi, M., Alesheikh, A. A., 2018. A New Site Selection Approach Based on Participatory Multi-Criteria Decision Making through Geosocial media- Case study: Shopping centers. International Journal of Geo-Information. Vol. 7(3), No. 82. Pp. $1-11$.

Opricovic, S., 2011. Fuzzy VIKOR with an application to water resources planning. Expert Systems with Applications. 38, 12983-12990.

Rajendran, S., 2006. Sustainable Construction Safety and Health Rating System. Oregon State University, Corvallis, Ore.

Rall, E., Hansen, R., Pauleit, S., 2019. The added value of public participation GIS (PPGIS) for urban green infrastructure planning. Urban Forestry \& Urban Greening. Vol 40, April 2019, Pages 264-274. 
Shahabi, H., Allahvirdiasl, H., Alizadeh, M., 2012. Application of GIS Models in Site selection of waste disposal in Urban Area. IOSR Journal of Applied Physics (IOSRJAP) ISSN - 2278-4861. Vol 1, Issue 6 (Sep.-Oct. 2012), PP 01-07.

Senvar, O., Otay, I., Bolturk, E., 2016. Hospital Site Selection via Hesitant Fuzzy TOPSIS. IFAC-PapersOnLine 49-12 (2016) $1140-1145$

Santos, G. S., Gomes, R. A., Santos, E. A., 2018. PPGIS as an urban planning tool around airports. Journal of Air Transport Management. Vol 69, June 2018, Pages 269-278. https://doi.org/10.1016/j.jairtraman.2017.07.005.

Sahin, T., Ocak, S., Top, M., 2019. Analytic hierarchy process for hospital site selection. Health Policy and Technology 8 (2019) 42-50.

Vahidnia, M.H., Alesheikh, A., Alimohammadi, A., Bassiri, A., 2008. Fuzzy analytical hierarchy process in GIS application. In: Proceedings of the International Archives of the Photogrammetry, Remote Sensing and Spatial Information Sciences, Vol. XXXVII. PartB2.Beijing 2008.

Zhou, F., Wang, X., Goh, M., 2018. Fuzzy extended VIKORbased mobile robot selection model for hospital pharmacy. International Journal of Advanced Robotic Systems. https://doi.org/10.1177/1729881418787315. 